\title{
Numerical Study of the Thermal Behavior of a Composite Phase Change Material (PCM) Room
}

\author{
Nidhal Ben Khedher \\ Mechanical Engineering Department \\ College of Engineering \\ Hail University \\ Hail, Saudi Arabia \\ Laboratoire d'Études des Systèmes Thermiques et Énergétiques \\ Ecole Nationale d'Ingénieurs de Monastir \\ University of Monastir \\ Monastir, Tunisia \\ N.khedher@uoh.edu.sa
}

\begin{abstract}
In this study, thermal performance of building walls integrated with phase change materials (PCM) was evaluated in terms of indoor temperature reduction and heat transfer time delay. PCM was incorporated as thin layer placed longitudinally within walls. The thermal performance of a room with and without PCM was evaluated numerically. The developed model is based on the enthalpy formulation for PCM melting and solidification, which is solved by an implicit finite difference method. The effect of PCM type on heat gain indoors was studied. Three phase change materials (n-octadecane, n-eicosane and calcium chloride hexahydrate) were tested in hot weather. Results showed that octadecane is the best in ensuring an indoor temperature close to $27^{\circ} \mathrm{C}$ for the test room. Moreover, optimal thickness of the PCM layer within the walls is critical for heat transfer reduction and management and should be carefully chosen.
\end{abstract}

Keywords-PCM; passive cooling; energy storage; building

\section{INTRODUCTION}

Currently, research is focusing on the optimization of energy systems. One of the ways to save energy is the passive climate control. Consequently, passive air conditioning systems, in which phase change materials (PCMs) are used, have received particular attention in recent years [1-4]. The major reason for using these systems is the high energy capacity of some PCMs during melting or solidification, compared to sensible heat systems. Since, sensible heat storage requires large temperature differences. To raise these temperature differences consumes large amounts of energy. The advantage of some PCMs, which is the large heat capacity during phase change, is that the latent heat-cooling of PCM is more economical while allowing the storage and release of energy at a constant temperature. Integration of PCMs in buildings is an interesting way to reduce energy consumption or to improve comfort [5-7]. For PCMs, several criteria may be applied in order to select the appropriate one. Various PCM types have been explored for passive air conditioning, including hydrides, salts and their mixtures, acids, paraffin and non-paraffin. PCMs should have melting/freezing temperature in the practical range of application and they must have a high latent heat of fusion and a high thermal conductivity [8].

Several researches were conducted to study the thermal behavior of the PCM room in summer. Authors in [9] produced micro-encapsulated PCMs which were used in the room walls while another room without PCM was built as reference. The PCM room can decrease the maximum temperature by $4^{\circ} \mathrm{C}$ in summer. Authors in [10] experimentally investigated a new PCM wallboard, the experiments were carried out in a fullscale test room which was completely controlled. It was found that the indoor air temperature for the case without PCM fluctuated from 36.6 to $18.9^{\circ} \mathrm{C}$, whereas for the PCM case it is varying from 32.8 to $19.8{ }^{\circ} \mathrm{C}$. Authors in [11] tested PCMs with two typical construction materials for Mediterranean construction in real conditions. Several cubicles were built and their thermal performance was analyzed. For each construction material, macro-encapsulated PCM was added in one cubicle (RT-27 and SP-25 A8). Results showed that the PCM can reduce the peak temperatures up to $1{ }^{\circ} \mathrm{C}$ and reduce the daily fluctuations. Moreover, it can reduce the electrical energy consumption by about $15 \%$. Authors in [12] studied the effects of the encapsulated PCM on the thermal performance of a brick masonry wall. The influences of the phase change process of the PCM over the attenuation of temperature fluctuations and time constant were essentially evaluated.

This work deals with a numerical study of the thermal behavior of walls built with construction materials used in southern city in Tunisia (Gafsa) and in which PCMs were added. The model, based on the enthalpy formulation, is described by an equation of heat transfer which is solved by an implicit method of finite differences. We analyzed the influence of wall thickness and its composition as well as the effect of PCM materials on the evolution of the indoor temperature. 


\section{PHYSICAL MODEL AND MATHEMATICAL FORMULATION}

Indoor temperature is an important parameter for the notion of comfort. In order to study the efficiency of wall/PCM without ventilation, thermal behavior was simulated by determining the evolution of the interior temperature of a room.

\section{A. Physical Model}

In order to predict the evolution of the indoor temperature of a room built by walls containing the PCM, a composite PCM room is considered. The dimensions of this room are shown in Figure 1. The indoor temperature is calculated numerically by solving the equation of energy conservation of the air inside the room. The PCM wall is composed of two layers (Figure 1): An ordinary wall that contains brick and cement mortar $0.25 \mathrm{~m}$ thick and a layer of microencapsulated PCM inside the room with $0.01 \mathrm{~m}$ thickness.

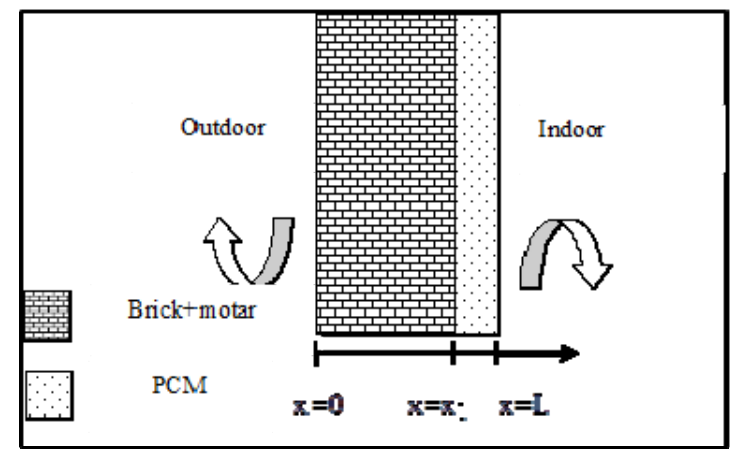

Fig. 1. PCM composite wall.

\section{B. Mathematical Formulation}

The heat transfer process is managed by the conduction phenomenon. The following assumptions were made when establishing the numerical model of the phase change process: 1) the heat transfer of the PCM envelop was one-dimensional, 2) the PCM was homogeneous and isotropic, 3) the convection effect in the molten PCM was neglected, 4) the thermophysical properties of the PCM are constant except the specific heat capacity during the melting and freezing process. The computational domain to be studied is composed of two sub domains (ordinary wall and PCM layer):

- $\quad$ For ordinary wall (brick + mortar)

The energy equation:

$$
\rho_{b} \mathrm{C}_{p b} \cdot \frac{\partial T_{b}}{\partial t}=\lambda_{b} \frac{\partial^{2} T_{b}}{\partial x^{2}}
$$

- For the PCM layer

The numerical model was established by the sensible heat capacity method, the governing equation is:

$$
(\rho C)_{P C M, e f f} \frac{\partial T_{P C M}}{\partial t}=\lambda_{P C M, \text { eff }} \frac{\partial^{2} T_{P C M}}{\partial x^{2}}
$$

The expression of $(\rho c)_{P C M, \text { eff }}$ for the PCM is defined as below:

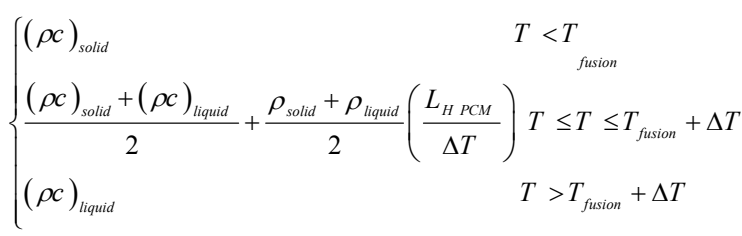

knowing that $\Delta \mathrm{T}$ is the is the melting temperature range.

\section{1) External conditions}

The outdoor side of the wall is subjected to a time dependent radiation and forced convection boundary conditions, with $h_{o}=20 \mathrm{~W} / \mathrm{m}^{\circ} \mathrm{C}$. The indoor surface is a free convection boundary condition with $h_{i}=10 \mathrm{~W} / \mathrm{m}^{\circ} \mathrm{C}$. The heat flow into the outdoor wall can be expressed as (3) or (4):

$$
\begin{aligned}
& Q_{\mathrm{os}}=Q_{\mathrm{conv}}+Q_{s}-Q_{\text {Correc }} \\
& Q_{\mathrm{os}}=h_{o} A\left(T_{o}-T_{\text {os }}\right)+\alpha A q_{s}-\varepsilon A \sigma\left(T_{o}^{4}-T_{\text {surr }}^{4}\right)
\end{aligned}
$$

where $T_{o}$ is the outdoor air temperature, $T_{o s}$ the outdoor surface temperature, $\alpha$ the solar absorptivity of the wall surface, and $q_{s}$ is the solar flux radiation. The last term in (4) represents the correction for the radiation heat transfer when the surrounding and the ambient temperatures are not equal. It is assumed that these two temperatures are equal in this study. The heat flow into the outdoor surface can be expressed as:

$$
Q_{\mathrm{os}}=h_{o} A\left(T_{s}-T_{o s}\right)
$$

where $T_{s}$ is the solar-air temperature, which is defined as:

$$
T_{s}=T_{o}+\alpha \frac{q_{s}}{h_{o}}
$$

The boundary conditions were:

- Interface wall/PCM:

$$
\left.\lambda_{P C M, \text { eff }} \frac{\partial T_{P C M}}{\partial x}\right|_{x=x_{1}}=-\left.\lambda_{b} \frac{\partial T_{b}}{\partial x}\right|_{x=x_{1}}
$$

- Interface outdoor/wall:

$$
-\left.\lambda_{b} \frac{\partial T_{b}}{\partial x}\right|_{x=0}=h_{\text {out }}\left(T_{b}-T_{\text {out }}\right)
$$

2) Model of the Indoor Air:

The energy conservation equation for the indoor air is:

$$
\rho_{a} C_{p} \mathrm{~V}_{\mathrm{R}} \frac{d T}{d t}=\sum_{i=1}^{N} Q_{w, \mathrm{in}}+Q_{s, i n}+Q_{L}+Q_{w i n}
$$

where $V_{R}$ represents room cubage, $Q_{w, \text { in }}$ the convection heat transfer rate between air and inner surfaces of the room, $Q_{s, c}$ the convection heat transfer rate from the indoor heat source, $Q_{L}$ the heat transfer rate by air leakage and $Q_{\text {win }}$ the 
heat transfer rate through the window. $Q_{w, i n}, Q_{L}$ and $Q_{w i n}$ are calculated by the following equations:

$$
\begin{aligned}
& Q_{w, \text { in }}=h_{i} \times\left(T_{w, i}-T_{i}\right) \times A_{w, i} \\
& Q_{w i n}=A_{w i n} \times\left(T_{o}-T_{i}\right) \times U_{w i n} \\
& Q_{\text {Leakage }}=\rho_{a} C_{p} \mathrm{~V}_{\mathrm{R}} \times A C H \times\left(T_{o}-T_{i}\right) \\
& Q_{s, i n}=\sum_{i=1, n b t} P_{i}
\end{aligned}
$$

where $T_{w, i}$ is the inner surface temperature of a wall, ceiling and floor while $A_{w, i}$ is its area. $U_{w i n}$ and $A_{w i n}$ are overall heat transfer coefficient and the window area the respectively. $P_{i}$ is the heat generation rate by the equipment.

\section{NUMERICAL TREATMENT}

The equations set, with initial and boundary conditions have been solved numerically using the finite difference method.

$$
\lambda \frac{\partial^{2} T}{\partial x^{2}}=\lambda \frac{T^{+}{ }_{i+1}-2 T_{i}^{+}+T_{i-1}^{+}}{\Delta x^{2}}
$$

The energy equation after discretization:

$$
\rho c_{p} \frac{T_{i}^{+}-T_{i}^{0}}{\Delta t}=\lambda \frac{T_{i+1}^{+}-2 T_{i}^{+}+T_{i-1}^{+}}{\Delta x^{2}}
$$

After factorization the energy equation becomes:

$$
\lambda \frac{T_{i-1}^{+}}{\Delta x^{2}}-\left(\frac{\rho c_{p}}{\Delta t}+\frac{2 \lambda}{\Delta x^{2}}\right) T_{i}^{+}+\lambda \frac{T_{i+1}^{+}}{\Delta x^{2}}=\rho c_{p} \frac{T_{i}^{0}}{\Delta t}
$$

The resulting algebraic system from assembling the contributions of all sub-volumes has the following general form

$$
a_{i} T_{i-1}^{+}+b_{i} T_{i}^{+}+c_{i} T_{i+1}^{+}=d_{i}
$$

with

$$
a_{i}=\frac{\lambda}{\Delta x^{2}}, b_{i}=-\frac{2 \lambda}{\Delta x^{2}}-\frac{\rho c_{p}}{\Delta t}, c_{i}=\frac{\lambda}{\Delta x^{2}}, d_{i}=\frac{-\rho c_{p} T_{i}^{0}}{\Delta t}
$$

The discretization of the heat equation over the entire domain allows us to obtain a tri diagonal matrix system. The resolution of this system was made by Thomas's algorithm known by TDMA (tri diagonal matrix algorithm).

\section{RESULTS AND DISCUSSION}

The effectiveness of the PCM brick is evaluated by representing the indoor temperature evolution during three days of summer (July 2017) of a typical room situated in a Tunisian southern city (Gafsa). The room dimension are $5.0 \mathrm{~m}$ (length) $\times 3.0 \mathrm{~m}$ (width) $\times 3.0 \mathrm{~m}$ (height). The room walls are built from PCM brick (brick impregnated with PCM). Total indoor heat generation rate by equipment, light and occupants etc. is assumed to be $100 \mathrm{~W}$. The typical day weather of July in Gafsa, is chosen as the outdoor climate data. Hourly variation of outdoor air temperature and solar radiation are shown in Figure 2. Table I lists the main parameters of the studied room.

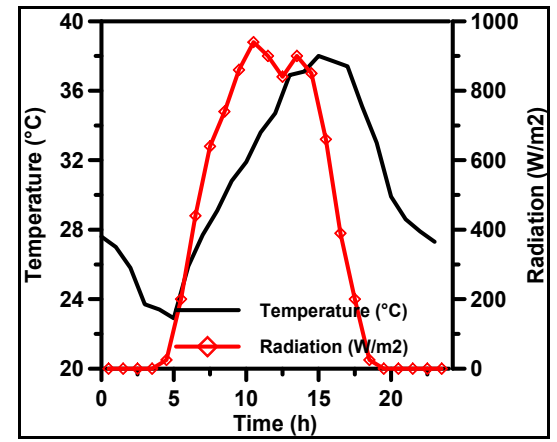

Fig. 2. Hourly variation of solar radiation and ambient temperature for a typical day of the month of July 2017 for Tunisian southern city Gafsa

\section{A. Effect of PCM Type}

\begin{tabular}{|c|c|c|c|c|c|}
\hline Material & Melting Temprature $\left({ }^{\circ} \mathrm{C}\right)$ & $\lambda\left(\mathbf{W} / \mathbf{m}^{\circ} \mathbf{C}\right)$ & $\mathrm{C}_{\mathrm{P}}\left(\mathrm{KJ} / \mathrm{KgC}^{\circ}\right)$ & $\rho(\mathrm{Kg} / \mathrm{m} 3)$ & $\mathbf{L}_{\mathrm{H} M C P}\left(\mathrm{~kJ} / \mathrm{c}^{\circ}\right)$ \\
\hline Brick wall & - & 1.15 & 0.84 & 1600 & - \\
\hline n- Octadecane & 27 & $\begin{array}{l}0.385 \text { (solid), } \\
0.148 \text { (liquid) }\end{array}$ & $\begin{array}{l}1.934 \text { (solid), } \\
2.196 \text { (liquid) }\end{array}$ & $\begin{array}{l}865 \text { (solid) } \\
780 \text { (liquid) }\end{array}$ & 243.5 \\
\hline n-Eicosane & 37 & $\begin{array}{l}0.15 \text { (solid), } \\
0.15 \text { (liquid) }\end{array}$ & $\begin{array}{l}2.01 \text { (solid), } \\
2.04 \text { (liquid) }\end{array}$ & $\begin{array}{l}778 \text { (solid) } \\
856 \text { (liquid) }\end{array}$ & 241 \\
\hline $\begin{array}{l}\text { Calcium chloride hexahydrate } \\
\mathrm{CaCl}_{2} 6 \mathrm{H} 2 \mathrm{O}\end{array}$ & 29 & $\begin{array}{l}1.09 \text { (solid), } \\
0.54 \text { (liquid) }\end{array}$ & $\begin{array}{l}2.4 \text { (solid), } \\
2.04 \text { (liquid) }\end{array}$ & $\begin{array}{l}1710 \text { (solid), } \\
1500 \text { (liquid) }\end{array}$ & 164 \\
\hline
\end{tabular}

The effectiveness of the PCM/wall system is evaluated by comparing the heat flux at its internal surface with that of a regular wall without PCM. The melting temperature of the three PCMs chosen is close to the ambient temperature of a summer day. Thermo-physical properties of these PCMs are summarized in Table I

TABLE I.

THERMAL PROPERTIES OF WALL AND PCMS

Figure 3 shows the variation of the indoor temperature for different PCMs with layer thickness equal to $1 \mathrm{~cm}$. It is clearly noticed that the addition of PCM to a wall results in the stabilization of the indoor temperature to a much lower temperature than that of an ordinary wall. In addition, it is noticed that octodecane stabilizes the internal temperature to a temperature close to its melting temperature. This result shows that octodecane stores heat in latent form by fusion at a constant temperature equal to its melting temperature. From Figure 4, it is clear that octadecane is the more effective when compared to other tested PCMs. Since it has the most suitable melting temperature for the operating conditions (external 
temperature varies between $45^{\circ} \mathrm{C}$ and $20^{\circ} \mathrm{C}$ ). Moreover, the resulting indoor temperature lies in the comfort zone. For this reason we will choose the octadecane for the remaining tests.

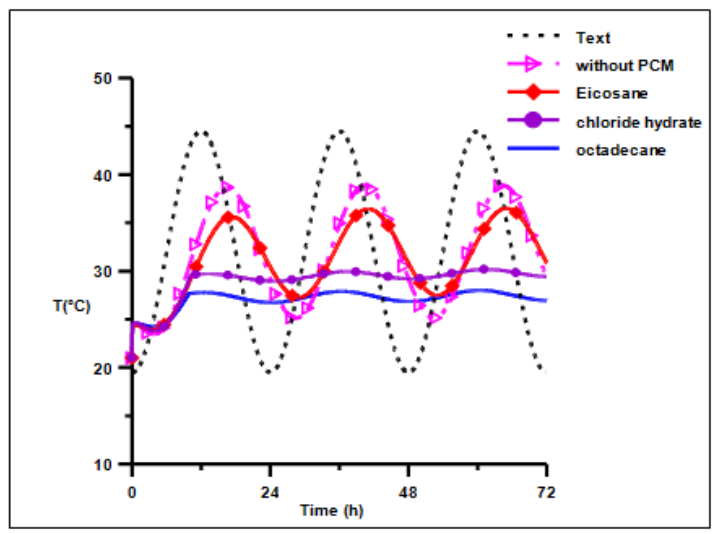

Fig. 3. Simulated hourly indoor air temperature for various types of PCM

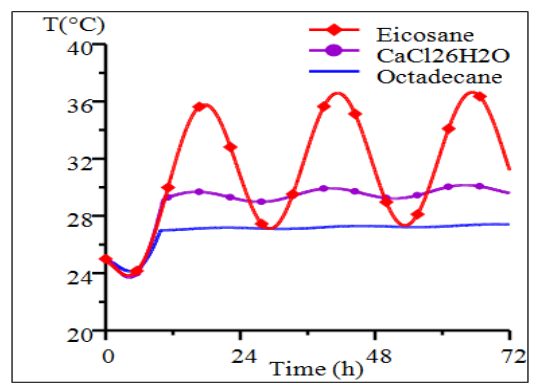

Fig. 4. Evolution of the PCM temperature at the node in the interior

\section{B. Effect of PCM Layer Thickness}

The study of the influence of the PCM layer thickness on the variation of the internal temperature is very important for the optimization of wall/PCM performance. From Figure 5 it is noted that the internal temperature for thickness equal to 0.5 $\mathrm{cm}$ has a peak and an overheating of 4 degrees after three days of operation. This behaviour is justified by the fact that the mass of octadecane for this thickness $(0.5 \mathrm{~cm})$ is not sufficient to store all the heat coming from the outside during three hot days of operation. Consequently, extra heat is stored in the sensible form. Hence the sudden increase in the internal temperature is noticed. However, for thickness greater than or equal to $1 \mathrm{~cm}$, there is practically the same change in the indoor temperature. So, the thickness of PCM layer should be carefully optimized because of the high PCM cost. Since, with $2 \mathrm{~cm}$ thickness we have the same indoor temperature as with $1 \mathrm{~cm}$, it can be concluded that there is an optimum thickness allowing maximum efficiency and minimal economic cost.

\section{CONCLUSION}

PCMs used in buildings can enhance indoor thermal comfort and reduce energy consumption for space cooling and heating. In present research, a detailed study of three PCM layers combined in the building envelopes has been carried out to analyze the thermal performance in a typical city in Tunisia during summer. Generally, the efficiency of PCM application depends on the PCM selection of suitable melting/freezing point and latent heat. To enhance the applicability of walls fitted with a thin layer of PCM, a theoretical investigation of mathematical model has been explored in detail. Current research finds that the octadecane layer with $1 \mathrm{~cm}$ thickness performs well for the test room. PCM layer thickness is a critical parameter which should be carefully optimized.

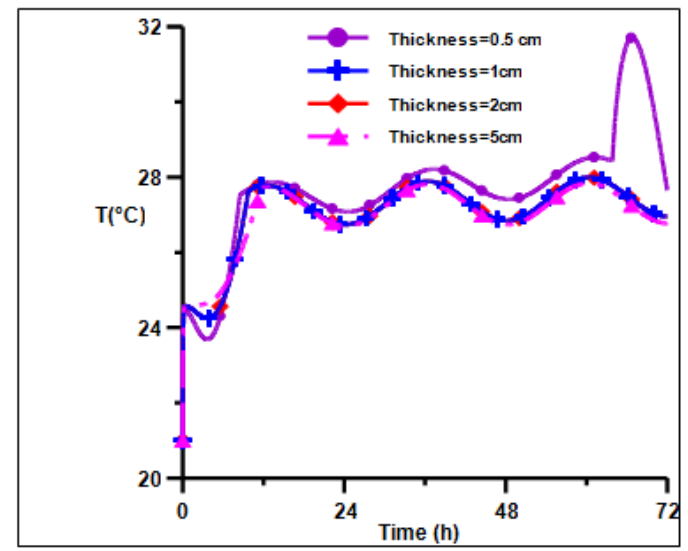

Fig. 5. Hourly variation of solar radiation and ambient temperature for a typical day of July 2017 for Gafsa

\section{REFERENCES}

[1] N. Soares, J. J. Costa, A. R. Gaspar, P. Santos, "Review of passive PCM latent heat thermal energy storage systems towards buildings' energy efficiency", Energy and Buildings, Vol. 59, pp. 82-103, 2013

[2] F. Kuznik, D. David, K. Johannes, J. J. Roux, "A review on phase change materials integrated in building walls", Renewable and Sustainable Energy Reviews, Vol. 15, No. 1, pp. 379-391, 2011

[3] E. Oro, A. de Gracia, A. Castell, M. M. Farid, L. F. Cabeza, "Review on phase change materials (PCMs) for cold thermal energy storage applications", Applied Energy, Vol. 99, pp. 513-533, 2012

[4] C. Wani, P. K. Loharkar, "A Review of Phase Change Materials as an Alternative for Solar Thermal Energy Storage", Materials Today: Proceedings, Vol. 4, No. 9, pp. 10264-10267, 2017

[5] Y. Cui, J. Xie, J. Liu, S. Pan, "Review of Phase Change Materials Integrated in Building Walls for Energy Saving", Procedia Engineering, Vol. 121, pp. 763-770, 2015

[6] C. Amaral, R. Vicente, P. A. A. P. Marques, A. Barros-Timmons, "Phase change materials and carbon nanostructures for thermal energy storage: A literature review", Renewable and Sustainable Energy Reviews, Vol. 79, pp. 1212-1228, 2017

[7] A. M. Khudhair, M. M. Farid, "A review on energy conservation in building applications with thermal storage by latent heat using phase change materials", Energy Conversion and Management, Vol. 45, No. 2, pp. 263-275, 2004

[8] Y. Zhang, G. Zhou, K. Lin, Q. Zhang, H. Di, “Application of latent heat thermal energy storage in buildings: state-of-the-art and outlook", Building and Environment, Vol. 42, No. 6, pp. 2197-2209, 2007

[9] V. V. Tyagi, D. Buddhi, "PCM thermal storage in buildings: a state of art", Renewable and Sustainable Energy Reviews, Vol. 11, No. 6, pp. 1146-1166, 2007 
[10] F. Kuznik, J. Virgone, J. J. Roux, "Energetic efficiency of room wall containing PCM wallboard: a fullscale experimental investigation", Energy and Buildings, Vol. 40, No. 2, pp. 148-156, 2008

[11] A. Castell, I. Martorell, M. Medrano, G. Perez, L. F. Cabeza, "Experimental study of using PCM in brick constructive solutions for passive cooling", Energy and Buildings, Vol. 42, No. 4, pp. 534-540, 2010

[12] R. Vicente, T. Silva, "Brick masonry walls with PCM macrocapsules: an experimental approach", Applied Thermal Engineering, Vol. 67, No. 12, pp. 24-34, 2014 